\title{
Dos relatos, un análisis y un excurso sobre las identidades y la relación con la ciudad entre los "moradores de la calle" en Temuco, Chile ${ }^{1}$
}

\section{Two tales, an analysis and an excursus on identities and the relationship with the city among "street-dwellers" in Temuco, Chile}

Marcelo Berho C. ${ }^{2}$

Aceptación: 15 diciembre 2009

Aprobación: 25 abril 2010

\section{RESUMEN}

El autor describe dos casos de personas que viven en la calle en la ciudad de Temuco, en el centro sur de Chile. A partir de una perspectiva etnográfica indaga en algunos de sus modos de acción e interacción en la ciudad, mostrando la lógica de sus actos y la forma en que éstos hacen parte de complejos y fragmentados procesos de configuración identitaria. Asimismo, el autor desarrolla un análisis que estimula el extrañamiento y cuestiona algunos supuestos y conceptos socialmente dados por garantizados respecto de la relación entre los "moradores de la calle" y la ciudad. En este marco, defiende la tesis según la cual la sobrevivencia es un proceso totalizador que trasciende la esfera biológica para articular un estilo de vida en la que el yo y la ciudad son objetos resignificados en función de una serie de experiencias límite a través de las cuales podemos aprender más de nuestro propio mundo.

Palabras clave: Moradores de la calle, identidad, trayectorias.

\begin{abstract}
The author describes two cases of homeless in Temuco city, in the south-center of Chile. From an ethnographic perspective, he investigates some of their ways of action and interaction in the city, showing the logic of their acts and the way in which they become a part of complex and fragmentary identity configuration processes. Likewise, the author develops an analysis that stimulates the strangement and questions some assumptions and some concepts socially taken for granted about the relationship between the homeless (street dwellers) and the city. It is within this framework that he defends the thesis according to which the survival is a totalizing process which transcends the biological sphere, in order to articulate a way of life in which the "oneself" and the city are re-signified objects in relation to of some limit experiences, through which we can learn more from our own world.
\end{abstract}

Key words: Homeless, street dweller, identity, trajectory.

Este texto ha sido elaborado en base al material etnográfico acumulado a partir de una investigación de campo antropológica en torno a las personas que viven en la calle, realizada en la ciudad de Temuco, Chile, en diferentes momentos desde 冈nes de 1997 a 2005. En la mayor parte de estos acercamientos he contado con el apoyo de la Universidad Católica de Temuco y de entidades públicas de la región y la comuna.

2 Antropólogo, Docente Universidad Católica de Temuco. Actualmente es doctorando del programa de Doctorado en Ciencias Sociales de la UNGS - IDES, Buenos Aires, Argentina. mberho@uct.cl 
Primer relato. "Ejercitar el don de las extremidades para estar a nivel"

La primera vez que me acerqué a $\mathrm{C}$ fue una tarde otoñal de 1998, de esas de comienzos de la estación que aún ceden un poco de espacio a los rayos del sol. C estaba en la bencinera de Caupolicán y calle Imperial, en la ciudad de Temuco. Llevaba consigo un enorme equipaje de desechos que, como más tarde me diría, había recogido "en la ciudad". Ya lo había visto en un par de oportunidades, pero no había encontrado pretexto para abordarlo. Ahora tampoco tenía pretexto, pero mi voluntad fue más fuerte. Me había llamado mucho la atención su estética. Su estilo abigarrado, caracterizado por llevar trajes hechos por él mismo en los que sobresalían nudos y amarras de las que pendían objetos cada vez más increíbles. De un poco más de cincuenta años, C era un hombre pequeño y delgado. Tanto su cara y cabeza como sus manos y pies tenían ya sedimentado el paso de varias temporadas de vida a la intemperie en el centro-sur de Chile. Me diría que venía de Talca y que habría llegado caminando a Temuco en 1993. Tuve la sensación de estar hablando con un hombre que no había sostenido relaciones sociales desde hacía mucho tiempo. Observé su pasividad y quietud y la humildad que emanaban de su presencia, haciéndolo aparecer como una figura para nada indiferente a los ojos de cualquier transeúnte, no pudiendo captar menos que el interés apasionado de un etnógrafo dispuesto a ver al hombre detrás de la rareza. Porque para cualquiera que lo veía, C era raro, muy raro, un freak según los adolescentes de ahora. En ese tiempo $C$ se había ganado el apelativo de "Señor Basura", "Capitán Inmundo". Para otras personas que por casualidad se cruzaban con él -como el portero de un colegio, un zapatero y un cuidador de autos-, aparecía como "enfermito" y "loco". Pero ¿era realmente así?

En ese primer encuentro nos presentamos. Hablamos un poco de quién era cada uno y qué hacíamos. Su voz era suave y un poco entrecortada. Sus ojos jamás miraron los míos. Movía su cabeza de un lado a otro, como esquivándome. Sus palabras salían de su boca sin premura. Yo apenas lo podía escuchar. Cada vez que, por lo mismo, intentaba acercarme un poco más a él, se echaba un paso más atrás, de tal manera que durante toda la conversación mantuvimos siempre una distancia más o menos fija. Si bien no olía a alcohol, su presencia entera expelía hedor. Observé que el cargamento que llevaba consigo era literalmente de desperdicios. Y que, según él mismo, eran "materiales de la ciudad". Hubo aspectos de él mismo que no pude oír a causa del bajo volumen de su voz y del ruido de los autos y camiones que atravesaban la avenida a esa hora. Me sentí un poco incómodo por preguntarle cosas, por mi actitud inquisitiva. Traté de no presionarlo. Dentro de todo lo que dijo, le entendí claramente que él vivía cerca de donde estábamos. Me quedé tranquilo porque supuse que podría volver a verlo si venía a esperarlo. Y así fue. En adelante seguí encontrándome con él en diferentes puntos de un área más o menos amplia que abarcaba parte del sector sur-oeste, la Avenida Caupolicán (Panamericana Sur) y algunas calles del centro de la ciudad.

Nunca pude saber si C podía dormir bien en su "aposento", como llamaba al lugar en que, justo en los límites de la ciudad y la comuna, dormía y acumulaba desechos ${ }^{3}$, pero lo cierto era que despertaba cada día muy temprano y que cada día solía hacer diferentes cosas que llenaban su tiempo y parecían darle razón a su vida. La mañana generalmente la ocupaba para "hacer ejercicios", literalmente. En un par de oportunidades lo acompañé mientras levantaba y trasladaba grandes rocas usadas en la contención de las aguas del río Cautín en invierno. En su "aposento" podía tener reservas de comida que encontraba en los tanques de basura. El agua la sacaba del río que tenía a metros, "aguas de vida", decía cada vez que bebía un sorbo o hablaba de ellas. Cuando levantaba rocas o trasladaba "materiales" de desecho, decía que eso era "ejercitar, hacer ejercicio" y "desarrollar el don de las extremidades". Se refería así a estar activo, a hacer cosas, a "no decaer", es decir, a estar en movimiento y sentirse vivo. Pero, ¿qué cosas hacía realmente C? Era el tipo de preguntas que, desde mis primeros encuentros con él, me hacía. Y, para saberlo, no

Se trataba de un costado inferior del puente Cautín, en la salida sur de Temuco. Este espacio había sido totalmente intervenido por $\mathrm{C}$ a través de la incorporación y yuxtaposición de objetos de desechos reutilizados por él con fines de sobrevivencia -entendida esta como una experiencia humana compleja que abarca facetas materiales, simbólicas y subjetivas-. 
quedaba más que ir en su búsqueda y quedarse con él todo el tiempo posible.

Tras levantar pesas, $C$ se iba a caminar. Una de las mañanas que estuve con él, lo acompañé por "las poblaciones" del sector Las Quilas, Amanecer y el sector de la Universidad de La Frontera. Atravesamos lentamente calles y avenidas y nos detuvimos en algunos puntos que antes ya habían captado mi atención. Primero, en una esquina de calle, al borde de una antigua avenida rota - para variar- por reparaciones, en cuya muralla figuraba una pequeña pintura hecha con tiza de color cuyo contenido era un retrato desprovisto de rasgos específicos, un rostro sin ningún trazo. C me dijo que la había hecho él. Por entonces, yo ya había advertido la forma como $C$ se simbolizaba a sí mismo diciendo que para él lo más importante era "desarrollar el don del lenguaje" y "el don de las extremidades". Igualmente, resultaba muy interesante y revelador que, entre otras designaciones, se definiera a sí mismo como "artista", "sastre" e "inventor". Esa vez me conmovió mucho saber que había sido él quien había dejado esa inscripción. Me satisfizo también el hecho de que entonces pudiera establecer con seguridad que otros dibujos similares que había visto en otros puntos del área hubiesen sido igualmente obra de él. Ahí nos quedamos un rato, casi absortos con la luz del sol. C absorbía la energía del sol; parecía dormido, o ensimismado, como tantas veces lo había visto y lo seguiría viendo.

Seguimos caminando, hasta llegar a la rotonda de Caupolicán, donde nos volvimos a detener. Allí había una pequeña feria de frutas y verduras, un colegio de adultos, una capilla, un supermercado; mucho flujo humano y de transportes. A unos metros del lugar en que nos detuvimos -que igualmente tenía un rostro dibujado con tiza, esta vez con una pipa en la boca (y que me hizo recordar la disposición artística de C)- había un tanque de basura rebosante de restos orgánicos dejados por los locatarios de la pequeña vega. C inició su incursión un poco tímidamente -infiero que a causa de mi presencia-. Mas, pronto no pudo seguir con su excavación, decidió introducirse al tanque, para lo cual me pidió ayuda. Una vez dentro de este, escarbó, hurgó y separó minuciosamente lo que se llevaría consigo. Encontró manzanas y naranjas un poco pasadas, hojas de lechuga y repollo, papas viejas y uno que otro "material" para sus "inventos": una pequeña botella de vidrio, un poco de hilo de nailon, una revista, un trozo de madera que más tarde usaría para hacer un tallado que en otra oportunidad me obsequiaría. Tras esto volvimos al muro en que estaba la pintura. Nos sentamos en el suelo cubierto de hojas; no había pasto. Le pregunté a $C$ si venía habitualmente allí. Me respondió afirmativamente, agregando que "había estado cortando el pastizal", lo que ofrecía una respuesta al hecho de que allí, en lugar de pasto, solo hubieran hojas. De inmediato sostuvo: "tengo pensado cortar un poco el pastizal de la ciudad... en eso estoy pensando porque está un poco largo... algo que haga en las calles, ya que me falta un poco de dinero (por entonces $-y$ después- no tenía ¡ni una chaucha!)... de alguna forma no hay que decaer, hay que mostrar un poquito el pensar... ya limpié un poco allí en la ciudad la otra noche..." ¿Dónde? -le pregunté-. "De la bomba [de bencina] pa'rriba, un poco allí limpié, saqué unos pastizales, pero después me voy a tirar más adentro pa' sacar todo eso... el otro año limpié bastante, saqué escombros y todo eso, dejé un poco limpio... a veces me demoro meses o años, pero estoy presente en todo eso" ( $C$, octubre de 2000). Estos "escombros" eran los restos que progresivamente había ido acumulando en su "patio", un lugar inmediatamente contiguo al "aposento", en el que tenía atiborrado de "materiales" (de desecho) recogidos en la ciudad y que, en mis primeras visitas, me había provocado náuseas debido al intenso hedor que de ahí emanaba y que, poco a poco, fui aprendiendo a "leer", y por cierto a soportar. Después de nuestra conversación, $C$ siguió solo hacia el centro de la ciudad, donde probablemente se dedicó a hacer una "limpieza".

"La primera vez que llegaba a la ciudad estaba tan necesitado y encontraba alimento bueno, sellado... Dije: 'Voy a limpiar todo esto, algo de pastizal y saber lo que voy a recoger ahí'... y ahí tenía una pequeña respuesta, todo eso me quedó, y hasta la hora, porque dije yo: 'yo tengo algo en el suelo o en mis manos, un privilegio del Señor'... Pensaba 'yo soy como mis padres y todos, aprendí muchas cosas y todo eso me va a informar, si pescar algo y me va a corresponder', dije yo, y de esa forma empecé a arreglar un poco el pastizal, las calles, 
todo eso y hasta la hora" (C, octubre de 2000). Como "limpiador" C se dedicaba no solo a arrancar el pasto, sino que también a recoger y llevar consigo escombros, neumáticos, fierros, envases de vidrio, latas, plásticos, ropa y diversos materiales virtualmente reciclables. Un par de veces incluso lo vi recoger animales muertos que después enterraba. Él decía que por más ínfima que fuese una criatura, en ella había vida, por lo que, al igual que los hombres, se merecía una sepultura digna. Posteriormente, observé a $C$ atravesar Avenida Caupolicán desde la biblioteca pública hasta la salida sur de Temuco, llevando consigo, trotando, un perro muerto amarrado a su espalda. Parecía uno más de los accesorios que portaba consigo (además de un cuchillo cartonero, una cadena de fierro al cuello y pulseras de acero amarradas en muñecas y tobillos). El perro era pequeño, llevaba el cuello torcido y de su boca corría un delgado hilo de sangre. Lo seguí todo el trayecto hasta su "aposento" donde le pregunté por el animal. Dijo: "este es un animalito que atropellaron y yo recogí para enterrar. Como este es territorio indígena, no puede quedar ahí tendido en la calle". No supe exactamente a qué se refirió C con esto último, pero no me cupo duda que el hecho de haber recogido el perro muerto y llevarlo consigo para sepultarlo tenía que ver con la visión "espiritualista" desarrollada por él como un mecanismo que le facilita la existencia" (Notas de campo, abril de 2001).

Los "materiales" los recogía tanto para "limpiar la ciudad" como para usarlos él mismo y, en ningún caso, para venderlos, como hacían otras personas que por entonces también frecuentaba. Este hecho, sumado a que $C$ no mendigaba ni tampoco contaba con ningún tipo de apoyo material de nadie, revelaba que él no usaba dinero. Y, en efecto, una vez que le quise dar plata me dijo que mejor le comprara algo, ya que a él le sería más difícil entrar a un negocio. Esa vez "conversamos del dinero y su posición era que él no lo necesitaba puesto que todo lo que requería para vivir lo encontraba "en la ciudad". Le pregunté cómo podía hacer eso y si realmente confiaba que la ciudad podía proveerle siempre de lo necesario. Con un tono muy optimista se volvió hacia mí y dijo: “digamos que yo soy un poco prehistórico, como los prehistóricos, pero bien... pienso yo que lo más importante es el don de las extremidades, el don del lenguaje, saber orar, hacer oraciones, componer cantares, no decaer... y si todo eso me acontece yo digo 'estoy bien', entonces el hombre para qué quiere riquezas”. Agregó que "en la Biblia el Señor dice: "Deja oro o plata y sígueme", así es que no solo del pan vive el hombre" (C, marzo de 1999).

Mientras mantuve el contacto con $\mathrm{C}$ aumentó entre nosotros la confianza. Él sonreía cada vez que me veía llegar y paulatinamente se ponía más conversador y animado. Sin decírmelo, él me aceptaba cada vez más cerca suyo, a la vez que yo comprendía mejor lo que me decía. Disfrutaba escuchándolo hablar de cuestiones existenciales, las que por cierto se fueron transformando en un tema prioritario en nuestras conversaciones. La vida la entendía como un proceso en el que el pasado requiere ser olvidado y en el que el futuropresente debe ser imperiosamente proyectado en base a las pautas que él mismo ha creado. Salirse de este proyecto implica "caer en decadencia", "desviarse", "entrar en desvío" o dejar de "estar a nivel". De ser así, el propio sujeto y su (precaria) integridad terminarían disolviéndose en el caos de la nada, el sinsentido, el absurdo, la decadencia radical.

Para "no desviarse" o entrar al estado de decadencia, C realizaba oraciones o sostenía una comunicación espiritual con Dios o "el Señor", como él prefería llamarle a lo absoluto. En esta actividad C empleaba una parte importante de su tiempo, ya fuese que estuviera detenido o descansando, o bien se encontrara caminando o "limpiando". Si bien nunca escuché a $C$ decir una oración, sí pude registrar el uso que él hacía de los símbolos religiosos y los contextos en los que los inscribía. "Yo empecé a orar del 93 pa'cá... me sentía tan mal y confuso. Oré, oré, oré día y noche y ahora me siento otro, digamos con otro semblante, pobre de bolsillo, pero eso no es todo puh... yo tenía en el cielo mucha riqueza y eso no era todo, no ve que en el libro de la Biblia dice el Señor: 'deja oro o plata o madre o padre y sígueme' y 'del comer o del pan no vive la persona' dice, sino 'de toda palabra', dice el Señor, y eso es una verdad que habla los misterios de la Biblia, las oraciones espirituales y por eso me siento otro yo ahora" (C, octubre de 2000).

Los "cantares" eran composiciones melódicas de un tono verdaderamente extemporá- 
neo que evocaba un pretérito y un sitio remoto -contrastando absolutamente con los repertorios musicales de los otros hombres sin hogar que hasta entonces conocía-. En 1998 y 2000 conté con la aprobación de $\mathrm{C}$ para registrar algunos de sus "cantares". Estos eran melodías articuladas en una lengua sin referente cuyos tonos y sonoridad -entre gitano y juglar medieval- tendían, desde la primera vez que los escuché, a erizarme los pelos. C ligaba directamente estos "cantares" con el libro bíblico del "Cantar de los cantares". La primera vez que registré un "cantar" de $\mathrm{C}$, le pregunté cómo era cada día para él y cómo se veía él en la sociedad. Me dijo: "comparto con mi presencia, veo las calles y todo eso y veo lo que recojo ahí a veces, materiales y veo lugares y digo que también tuve relaciones... y ahora que tengo que estar solo... el Señor es una respuesta y solo a Él pido oraciones, siempre, así que cuando me voy a acostar hago oraciones y todo eso, así que no puedo estar sin oraciones... El Señor anda con señales... quizá son señales de Él, igual que nazca un chancho, un pequeño animalito, distintos fenómenos, una planta o cualquier cosa, son señales del Señor, digamos... esa es la verdad, para que sea construida en oración, siempre fiel a Él porque vino a mí... la era fue muerte, digamos, así que todo eso dejó en oraciones, en la Biblia, los Apóstoles, los Santos, todo eso acontece... Ud. ve que hay millares de iglesias católicas, y yo me doy cuenta..." (C, octubre de 1998).

Una vez que reunidos y seleccionados diversos "materiales", C se hallaba en condiciones de "hacer un invento". Al definirse a sí mismo como "sastre", "artista" (de hecho su nombre lo tomó de un actor de cine) e "inventor", C me enseñaba que la dimensión física presente en el "atleta" o en alguien que "desarrolla el don de las extremidades" no es la única que puede asegurar la vitalidad de su ser, sino que también debe considerarse lo que él entendía como el "don del lenguaje" como vehículo y lugar donde cohabitan el pensamiento y la espiritualidad. La necesidad de tener que crear $y$, por tanto, no permanecer inmóvil está asociada, de nuevo, con la idea de que, de no ser así, la persona se disolvería. C sentenció una vez que "si no hiciera un invento, yo creo que no podría seguir, decaería, yo creo que la atmósfera me olvidaría". Algunos de sus "inventos" consistían en hacer bolsas de género y otros artefactos (hechos a su vez de otros artefactos). Asimismo, su ropa era mayoritariamente confeccionada por él. En una fotografía de 1998, C lleva una especie de coraza armada con diferentes fragmentos de géneros, bolsas de plástico, alambres y vegetales secos; sus pantalones son de franela envueltos en bolsas de agroquímicos. Lleva un zapato de un tipo y otro de otro y en uno de ellos se asoman los dedos del pie. En otras oportunidades ha llevado adheridas a su ropa diferentes creaciones: un pequeño cráneo de gato que llevó atado por algún tiempo a su pecho con alambre, o el disco de la cadena de una bicicleta como parte de su coraza. El perro que había llevado atado a sus espaldas era visto por él como otro de sus "talismanes". El "transistor de imágenes" o la botellita con arena que colgó a su pecho, así como las "pulseras" y "ropajes", servían todos a un fin tanto preventivo como terapéutico ligado a la búsqueda y mantenimiento del bienestar y la continuidad vital.

\section{Segundo relato. "Vivo ahí, duermo allá"}

P era en 1998 un gracioso hombre de 60 años oriundo de Quillota, "pero ponle tú que no soy de ni un lado" - se apresuraría a agregar en uno de nuestros primeros encuentros-, que llegó a Temuco "sin saber cómo" a comienzos del mismo año. Lo conocí en la feria Pinto ${ }^{4}$, en el barrio antiguo de Temuco. Yo andaba haciendo uno de mis recorridos habituales. Era mediodía y ya venía de haber conversado con un par de "torrantitos"

Este es un espacio tradicional de comercio de productos agropecuarios al que concurren diferentes actores sociales, chilenos y mapuche, campesinos, comerciantes y compradores provenientes de sectores y localidades rurales aledaños y de la propia ciudad. Hay en él un terminal de buses rurales, la estación de ferrocarriles, supermercados, tiendas comerciales, mayoristas y minoristas, ferreterías, tiendas de ropa usada, bazar -conocido como "feria de las pulgas"-, cantinas y restaurantes. En fin, uno de los escenarios que el etnógrafo de las formas marginales del Temuco de hoy (y de ayer) está obligado a tener que reconocer.

5 El "torrante" o "atorrante" constituye una categoría nativa con la cual se designa a los "moradores de la calle" que presentan un estado de deterioro físico-psíquico y exclusión social. El torrante sin hogar encarna una identidad social y corporal desacreditada - aunque no plenamente privada de la posibilidad de su restauración-, basada en la frustración y 
finados hoy en día. Cuando lo vi por primera vez, estaba de pie en un paradero de colectivos de Barros Arana. Me llamó la atención que estuviera murmurando y que llevara una bolsa con un cuaderno. Lo observé durante un par de minutos desde el otro lado de la calle. Hasta ese momento no tenía todavía más indicios sobre su posible condición. De pronto comenzó a registrar el basurero del paradero. Esa acción estimuló mi deseo de cruzar a hablar con él. Cuando me acerqué a su lado, $\mathrm{P}$ tenía sus dedos untados con yogur. Hablamos un poco mientras seguía untando sus dedos en el yogur y llevándolos hasta su boca. Le hice algunas de las típicas preguntas que solía hacerles a las personas con las que buscaba entablar relación, cómo se llamaba, de dónde era, por qué estaba ahí, etc. Muchas de sus respuestas eran contradictorias, decía una cosa y luego agregaba otra de índole muy diferente, o afirmaba y a la vez negaba lo que decía. Hablaba muy rápido, como si por mucho tiempo hubiera mantenido asfixiadas las palabras y estas quisieran salir de una vez por todas de su boca sin más dilación. De todas las cosas que dijo en esa oportunidad no capté sino unas pocas: que tenía hambre, que no sabía dónde le podían dar comida, que dormía en cualquier parte y que en su cuaderno tenía escrito algo así como "el código de espina". (Con estos antecedentes supe que estaba ante uno de los "elegidos" para continuar mi trabajo.) Contando con su aprobación, en esa oportunidad lo llevé a un lugar en que le dieron almuerzo (y al que posteriormente seguiría asistiendo). Una vez allí, debió pasar por la entrevista de la asistente social y en seguida hacer una fila junto a otros "peregrinos" 6 . Dentro del comedor observé que $\mathrm{P}$ era del grupo de los que tenía "buenos modales", como algunos allí decían. (Este hecho se contraponía a la conducta de tomar con los dedos un yogurt encontrado en un basurero.) Se referían así no solo a los modales en la mesa sino, en general, a una actitud modelada por la educación cívica. "No porque estemos en la calle vamos a ser mal educados o a andar como los animales", era una conciencia entre algunos hombres que conocí... Como sea, comió en silencio, no habló con nadie y se repitió el plato. Cuando nos fuimos de allí, caminamos bastante. Partimos de la feria y llegamos a 18 de Septiembre, en plena Avenida Alemania. En el trayecto él se fue inspeccionando los basureros. Ese hecho me provocó risa y a la vez vergüenza: precisamente, dos formas como experimentamos y simbolizamos la presencia en la ciudad de gente como P. Sin preguntarle qué hacía, advertí que andaba en busca de revistas. Recogió una revista publicitaria de modas y otra "Muy interesante" manchada con café. Le pregunté si esas revistas tenían algo que ver con el cuaderno que llevaba guardado entre sus ropas. No me respondió nada.

Al otro día P era uno de los primeros en la fila para obtener almuerzo en el "comedor comunitario". Me sorprendió, pues, a juzgar por el día anterior, no esperaba encontrarlo ahí. Igualmente me causó gracia que llevara atado un palo a la cintura. Nos saludamos y hablamos brevemente. En el almuerzo volvió a ser amable y agradeció que le dejaran repetirse. Parecía no escuchar a sus pares, algunos de los cuales se habían insultado y vociferado mientras hacían la fila de espera. Le pregunté qué había hecho después de nuestro encuentro y me dijo que se había ido a descansar. No supe dónde exactamente, pero señaló un sitio lleno de escolares. Intuí que debía tratarse de algún lugar cercano a algún establecimiento educacional, de manera que, si dormía allí, ya tenía una idea de dónde ir a buscarlo en otra oportunidad ${ }^{7}$.

Cuando conseguí que $\mathrm{P}$ hablara de su cuaderno y del "código de espina", me explicó que, escribiendo una frase, y abajo poniendo el código correspondiente -que solo él conocía para cada caso-, él podría saber quién era

la resignación frente a "quedar afuera", la obstinación y el autoabandono a conductas socialmente reprochables, siendo la principal de ellas, en el caso de los “torrantes" de Temuco, la de beber alcohol en exceso. En la etnografía de las carreras marginales de personas sin hogar (Berho, 2000), advertí la incidencia de este aspecto en la emergencia y/o modificación de otros atributos y actitudes psicosociales.

6 Categoría nativa usada por los agentes institucionales del Hogar de Cristo para referirse a la población de "moradores de la calle" que habitualmente atienden. Este término ha sido reemplazado en la actualidad por el de "tío".

7 La experiencia del trabajo de campo hasta ese momento me había enseñado que la mejor manera de establecer los lugares de pernoctación de las personas era buscándolos al amanecer o a medianoche. Asimismo, había corroborado que el mejor momento para hablar con algunos de ellos, sobre todo con los "torrantes", era en la mañana, especialmente si de por medio había un café y un sándwich. 
yo y mi acompañante. Era de noche. Estábamos en los "puestos" (locales) de la feria. Más allá de nosotros pasaba un grupo de jóvenes "voluntarios de calle" - de los primeros que se formaba en Temuco-. Hacía un poco de frío, pero el ambiente parecía grato y seguro. $\mathrm{P}$ no paraba de hablar: de una camioneta doble cabina azul, de un joven, de una señora... Tras escribir algo en un papel que pidió, sin usar su cuaderno, puso sus dedos en aquel, lo tocó y murmuró... luego dijo que yo era "Efraín" y que mi acompañante era "Francisco", agregando que yo tenía que estudiar arquitectura. De este mismo modo afirmó haber alcanzado conocimiento de su enfermedad -más precisamente del "mal" que le hicieron-. Así pudo saber y darse cuenta que él tenía los órganos cambiados. "Cómo es eso?"-le pregunté-. "Así es puh, tengo el pulmón de uno, el hígado de otro y así.... Eso, advirtió, quiere decir que no estoy completo todavía..." (Notas de campo, mayo de 1998).

Con el tiempo, y tras verlo evocar el “código" cada tanto, comprendí que para él cualquier acción que emprendiese podía depender de los "códigos de espina", una especie de oráculo para prepararse ante cualquier eventualidad o situación vital e incluso llegar a saber el nombre de alguien o el estado de su propia salud o la de otro. Más allá de la certeza o demostrabilidad de sus enunciados y de que hablara sin parar y sin saber si me escuchaba o no, aprendí a reconocer algunos temas recurrentes en su discurrir lingüístico. Persistía en hablar sobre situaciones antes vividas, sobre épocas en que él trabajaba en una planta, en la fábrica o en la industria, cuando vivía en Quillota. Recordaba gente, nombres de calles y lugares; situaciones, escenas, cuadros vividos traídos al presente a través de un recuerdo retorcido - "unos hombres me vinieron a buscar en una camioneta, Chevrolet doble cabina... de ahí me llevaron, me sacaron de la fábrica... de ahí yo anduve con unos jóvenes que me preguntaban si tenía el papelito.."-; experiencias homosexuales; viajes a Valparaíso, a San Felipe, a San Pedro y a otros lugares; la llegada de su enfermedad y la naturaleza de la misma - "empecé a ver amarillo", "lo mío es un mal que me hicieron. Por la mente me dijeron que mi casa está embrujá y que todos tienen que irse de ahí"-; la jubilación que le hicieron - "Pinochet me dio la jubilación"- y que en la actualidad [primer semestre de 1998] no cobra, los documentos que él no firmó y los que sí firmó; [...] engaños y [...] tergiversaciones (¡no se de qué diablos!); los términos en que se efectuaron unas posesiones efectivas; [...] [Asimismo,] parece estar profundamente obsesionado con tarjetas de crédito, cuentas bancarias, números de series y de cuentas, códigos de barra, firmas y rúbricas, sellos y timbres de documentos y papeles (Berho, 1998b: 50-51). En otro momento (1999) escucharía hablar con igual o más vehemencia a $P$ sobre antenas, radares y transistores. Por entonces, como se dice vulgarmente, hablaba con locura de algunos temas y contratemas.

En menos de un año viviendo en las calles de Temuco, el aspecto de $\mathrm{P}$ cambió notoriamente. Sus barbas y cabellos crecieron visiblemente en un lapso de seis meses. Su tez y su contextura han cambiado. En ese intertanto se ha vuelto más moreno y enjuto. Sus manos se curtieron del polvo de la ciudad y de todo lo que pasa por ellas. Por entonces, se sometió a $\mathrm{P}$ a una entrevista psiquiátrica a partir de la cual se estableció un primer diagnóstico que, junto con otros elementos sociales y técnicos, posteriormente ayudarían a que $\mathrm{P}$ saliera de la calle... En la ocasión estuvo encendido, se hizo el simpático y gracioso, aunque en general creo no fue muy colaborativo con la "doctora". De todos modos, a nosotros nos brindó nuevas versiones de situaciones, momentos y procesos que había vivido y que seguían siendo actualizados por él cada vez que volvía a hablar de ellos. Se refirió a una situación con los carabineros de Quillota, al parecer durante los años de Frei, la enfermedad que sufre, la vez que lo llevaron en ambulancia a Putaendo. Opinó sobre momentos históricos vividos, nombró a los presidentes de Chile que han gobernado el país aproximadamente durante los últimos treinta años; relató por qué llegó a Temuco.

Para dar una idea vívida de su estilo, transcribo su voz: "Por represalia, por represalia, porque resulta parece que este caballero se le olvidó allá, porque yo había perdido... se me había hecho tira el papel de la jubilación... entonces yo fui para allá y me dio alojamiento y todo... faltaba que me diera mujer nomás... pero entonces yo sabía por 
la mente que el joven mayor parece que iba por ahí y los otros lolos iban después y hacían el amor... entonces fui para allá y estábamos en el comedor y estábamos conversando los dos solos, estábamos ahí en el comedor y entonces yo le dije a él cómo tenía que decir porque no sé si sabía, porque le dije 'oye'... le conversé que... por ejemplo si yo quería que él me haga el amor a mí yo no tengo que decirle a él. Eso le dije a ese niño, entonces se entusiasmó y me dijo "bueno"... pero resulta que eso es feo, ese caballero, padre o madre, llevan para allá a uno como allegado y no es mujer, puh, no es mujer..." (Entrevista psiquiátrica a $\mathrm{P}$, junio de 1998). Esa misma vez admitió que antes oía voces y que en el presente a veces también le pasa. Afirmó que era feliz como estaba, "vivo por ahí, duermo por allá". Por entonces, si bien era consciente de no tener dinero, no lo era mucho respecto de la situación de carecer de otros medios de subsistencia. La "doctora" corroboró lo que el sentido común había nombrado desde el principio con la palabra "locura". Dos días antes de la realización de esta entrevista $\mathrm{P}$ había comenzado a dormir en Los Traperos, uno de los dos refugios que entonces había para soportar el frío y la lluvia del invierno local ${ }^{8}$.

Pasado un año, $\mathrm{P}$ solo iba de repente a comer al Hogar de Cristo y prefería dormir en los "puestos" de la feria Pinto antes que ir a Los Traperos. Parecía sentirse bien. Se relacionaba con los "feriantes" (dueños de los puestos comerciales de la feria). Trabajaba para tres de ellos guardando la mercadería y lo hacía bastante bien. La gente le daba fruta, pescado o dinero y le convidaban agua cuando pedía. Al igual que $C$, seguía siendo un $N N$ (o indocumentado). A veces no olía nada bien. Su contextura física se mantenía, no había bajado de peso, como era el caso de otras personas en igual situación. Seguía siendo bueno para caminar. En todo ese tiempo me lo había encontrado en muchas partes: en la Avenida Alemania, en Caupolicán, en la Plaza de Armas - donde varias veces lo encontré hablando solo a las ocho de la mañana-, en la Plaza
Lautaro, en el centro. Si no estaba sentado, hablando solo, lo veía raudamente surcando calles, murmurando y deteniéndose a veces a escribir algo. Seguía siendo abstemio. Y todavía "transmitía" sobre cuentas bancarias, códigos de barra, códigos de identificación, cédulas de identidad, y un sinfín de elementos de la cultura moderna en los que parecían haberse quedado suspendidos algunos episodios de su historia más o menos cercana. Símbolos que remitían a no presencias, a problemas irrevocables sin solución, a fracturas y huecos biográficos. Como por entonces en realidad ya no valía la pena que le preguntara algo porque él hablaba y hablaba, prácticamente sin escuchar, decidí que cada vez que me encontrara con él simplemente lo dejaría hablar.

Como mi casa quedaba en el trayecto que él hacía cuando iba a dormir a Los Traperos, y ya había cierta confianza entre nosotros, un día se apareció por allí tocando el timbre. Esa tarde P calzaba unas botitas vaqueras color cobrizo, puntiagudas y con taco. Los pantalones los llevaba medio arremangados hasta los tobillos, de manera que dejaban ver el largo de las botas. Encima de la parka llevaba una capa de una tela semiimpermeable que había atado a su cuello. Llevaba puesto el gorro de la parka. Sus barbas largas le daban un efecto casi mágico, como si de pronto fuese a sacar una bola de cristal o un conejo de sus ropas. Llevaba además una bolsa con pescados que le habían dado en la feria. Esa vez, mientras compartimos una taza de té y pan, $\mathrm{P}$ acompañaba todo lo que decía con un gesto tan divertido y decidor con el momento que vivía. Cada vez que emitía frases llevaba hasta su boca alguna de sus manos poniéndola de tal forma que simulaba ser un altavoz. A su juicio, esa conducta respondía a que el volumen de su voz había bajado y requería por tanto ser amplificado. Desde entonces nunca más se supo de su cuaderno. Simplemente lo había perdido y ni siquiera lo recordaba. El contenido de ese cuaderno eran ilimitadas series de letras y números que ocupaban todo el espacio; también había textos, especies de

\footnotetext{
No es casualidad que la única hospedería que por entonces había en Temuco, Los Traperos de Emaús, recibiera y siga recibiendo más población que la que puede dar abasto durante los meses de invierno, desde junio a agosto.

$9 \quad$ Siguiendo este principio no solo me fue bien con $\mathrm{P}$, sino con la mayoría de las personas que viven en la calle que he conocido en Temuco. Queda pendiente aún el análisis del silencio y la escucha en la construcción del contexto etnográfico y su relación con otras dimensiones configuradoras (como la temporalidad, la violencia y el trauma), en la etnografía de la marginalidad extrema.
} 
poemas, antipoemas, pensamientos, antipensamientos. En una de las pocas oportunidades que tuve de ver su cuaderno rescaté frases como: "La banca se me rompió", "La casa está embrujada / Yo estoy en el cielo / y no vuelvo nunca más".

En 1999 había en Temuco tres hogares para personas sin hogar. De uno de ellos $\mathrm{P}$ terminaría siendo uno de sus residentes más queridos. Allí comenzó a experimentar evidentes cambios. Fue objeto de atenciones especiales por parte de sus encargados, quienes hicieron de él una especie de emblema de lucha, persistencia y compromiso. Ellos lo llevaron al médico y $\mathrm{P}$ inició un tratamiento psiquiátrico. En el hogar fue amado por su pasividad y docilidad, la que en su momento atribuimos a la medicalización a la que fue sometido por su desequilibrio. En efecto, tras un par de meses en el hogar, P dejó de "delirar", dejó de hablar solo y de levantarse a medianoche a caminar - como había ocurrido a su llegada-. "Era terrible como andaba aquí en la noche, quería irse, teníamos que sujetarlo entre los dos. Se levantaba como sonámbulo y decía groserías, no hallábamos qué hacer con él cuando lo trajimos" - me contó una vez la encargada del lugar-. Pienso que fue neutralizado con los "remedios", si no, no hubiese perdido el ánimo para levantarse, llegando a pasar una buena parte del tiempo acostado. La primera vez que lo fui a visitar no me reconoció, a pesar de que parecía hacer un enorme esfuerzo abriendo sus grandes ojos celestes para mirarme. Su cara estaba inflada y sus poros exudaban las toxinas del Tonaril, el Haldol y otros ungüentos de la farmacéutica con que se medica a los enfermos de esquizofrenia en los hospitales chilenos. Leía un poco la Biblia y participaba en los cultos que se hacían en el living del hogar, pero no tenía su espíritu puesto en nada de eso, al menos no como antes. Con el tiempo se iría restableciendo y podría hacerse cargo de algunas pequeñas tareas y deberes al interior del establecimiento: barrer, picar y acarrear leña, hacer algunas compras, cuidar los hijos de los encargados, entre otras. Trascurrido un tiempo, sus cuidadores se transformaron en sus "apoderados" legales. De esta manera, como exige la ley de discapacidad en Chile, pudieron hacerse oficialmente cargo de él y de su pensión como "discapacitado psíquico". Desde el 2003 que no lo he visto. Supe que seguía con los pastores en Padre Las Casas, en un hogar de ancianos.

\section{La identidad marginal extrema en la ciudad}

Los relatos que introducen este texto contienen algunos elementos que ayudan, por un lado, a retratar a las personas que viven en la calle desde un punto de vista antropológico explicitado (Berho, 2003b; Berho, 2005); y por otro lado, a abrir el diálogo con los nomarginales y coparticipar en la producción y disputa simbólica de concepciones y prácticas concretas sobre los "moradores de la calle" en tanto categoría social límite. Al verlo así, la etnografía se transforma en un esfuerzo intelectual de doble salida. Al explorar, penetrar y transitar por las diferentes densidades de la vida social y la cultura local (y nacional) en que tienen lugar las experiencias de los "moradores de la calle", el etnógrafo no solo desarrolla la misión cognoscitiva que tradicionalmente se le ha encomendado en el ámbito de la disciplina, sino que también se ve inmerso en tramas socioculturales en las cuales deberá desempeñar un papel diferente que paulatinamente irá aprendiendo a desplegar, sin desperfilarse de la trayectoria intelectual que precede a su trabajo y en el que la posibilidad de participar del diálogo social, político y cultural de la sociedad dominante se torna un desafío ética e intelectualmente ineludible. Así, lo que sigue constituye un relevo interpretativo orientado a destilar algunas cuestiones en torno a dos aspectos significativos: el proceso de configuración de la identidad de las personas sin hogar en relación con el espacio de la ciudad y algunas de las representaciones sociales dominantes en torno a aquellas.

En cada uno de los relatos se puede reconocer la existencia de una lógica de la ubicuidad relativa a la forma de habitar y simbolizar el espacio. Nuestra hipótesis es que tanto los desplazamientos como las prácticas que en ellos se despliegan, así como los motivos y concepciones que subyacen a los mismos son la expresión de identidades particulares, hijas de un proceso de desacoplamiento sociorrelacional y de una construcción de las inscripciones subjetivas e intersubjetivas que solo se da a través de una serie de fases analíticamente discernibles. ¿En qué consiste este proceso? ¿Cuáles son los momentos más rele- 
vantes que lo caracterizan? ¿De qué modo la ciudad se hace parte de este proceso y este a su vez de la ciudad? La etnografía de las trayectorias marginales aporta el material básico para visualizar los hitos y delinear el proceso en su totalidad (Berho, 2006).

Gran parte de la adaptación que requiere operar la persona concierne al modo como resolver las necesidades básicas. Una vez sin hogar, la persona debe enfrentar cada día la cuestión de la alimentación y la bebida, la protección, el abrigo, el descanso y la seguridad. Es más, debe decidir qué hará si no quiere morir. La persona descubre lo imperioso que es que la necesidad sea cubierta. Descubre también que para que así sea debe modular su conducta al entorno de "la calle". Esta comienza poco a poco a convertirse en un territorio para vivir de donde es posible extraer (casi) todo lo necesario para sobrevivir. La situación de $C$ es muy indicativa de esto, al punto de configurar una preferencia por hacer de la calle su hogar. Algunas personas, como P o C, parecieran resignarse plácidamente a vivir sin hogar, mientras que otras experimentan sendas crisis emocionales que solo alivian momentáneamente embriagándose, fantaseando o alienándose. Otros sienten deseos de morir o de acabar con la vida que llevan. Pueden ser muy críticos hacia la sociedad o ni siquiera presentir sus entrelazamientos. Durante esta fase las personas experimentan la discriminación social ligadas al cambio de su apariencia y conducta. Es lógico pensar que todas estas experiencias surtan profundos efectos sobre la configuración de la identidad social y subjetiva o que, más bien, este proceso esté íntimamente conectado con la adaptación que debe experimentar la persona en un sentido total, prácticamente ontológico. Sin poder determinar aún claramente como todo esto ocurre, podemos afirmar que lo que está en juego es la consistencia relacional y el sentido de la vida.

Como podemos inferir de los relatos cada trayectoria se va haciendo de diferentes materiales vitales y en ella están implicados actores, contextos y experiencias diversos en cuanto a formas y contenidos. En otra oportunidad (Berho, 2000), noté que la mayoría de la población había llegado a la calle debido a alguna crisis vital o a hechos biográficos de honda repercusión psíquica, experiencias en todos los casos más o menos intolerables: enfermedad, muerte de seres queridos, separación conyugal, quiebre económico. Las vivencias y sentimientos que acompañan este proceso parecieran ser correlativos con el nivel de estructuración del respectivo perfil identitario entre las personas. En este marco, las acciones de $\mathrm{C}$ y $\mathrm{P}$ adquieren consistencia propia $^{10}$. La adquisición de un estilo de vida marginal implica básicamente el desarrollo de estrategias de sobrevivencia -entre las cuales las económicas solo constituyen un tipo másy la resignificación de la calle, las experiencias de desvinculación y el sí mismo. "Durante la fase [que denominé] de desvinculación la persona experimenta una sensación de vulneración de su integridad que lo lleva a desarrollar una serie de estrategias de autoprotección sin las cuales el mundo inseguro de la calle sería prácticamente imposible de ser vivido y menos llegar a convertirse en un territorio existencial. Así, durante la fase de vulneración de la integridad la persona experimenta las consecuencias directas de su proceso de desvinculación del mundo de la vida social (familia, amistad, trabajo tradicional), así como de los sistemas sociales (asistencia social, salud, protección social): reproche y rechazo social, desprotección y exposición a las violencias urbanas de todo tipo (de los pares más jóvenes o más fuertes, de los sistemas de control social, de las pandillas juveniles, incluso de los perros)" (Berho y Samaniego, 2005: 109). Las estrategias económicas, en tanto, se caracterizan -como vemos en el relato de $\mathrm{C} y$ en parte en el de $\mathrm{P}$ - por desafiar los cánones ligados al mérito y la iniciativa productiva del capitalismo liberal. Más aún, C enseña que es posible vivir fuera del capitalismo: en verdad, con lo que este desecha.

En relación con la resignificación de la calle como territorio existencial, observamos que esta es una afirmación que hacen, en general, quienes ven en la calle un contexto que, a pesar de su violencia, acoge a los más desposeídos. "La calle es mi madre" -me señaló una vez $\mathrm{E}$, un "torrante" hoy finado-. La

\footnotetext{
10 Me aventuraría a señalar que si la persona ha soportado las fases de ruptura inicial y la de consecuente desmembramiento o desafiliación socioafectiva y socioeconómica advertida por otros especialistas (Cabrera, 1998; Castel, 1999), entonces la persona está dispuesta a la adquisición de un estilo de vida marginal.
} 
calle, en este sentido y a pesar de todo lo que podemos imaginar los que no vivimos en ella, es resignificada como contexto de estabilidad, como un territorio que tiene su propio recorrido: con una partida, una estancia, planicies, pliegues y un final. La seguridad que prodiga la madre, la calle también la puede dar. Como C sabía y como P tuvo que aprenderlo: es cosa de saber dónde buscar, a quién recurrir, a qué horas producir los desplazamientos, cuándo y cómo entrar en escena y cuándo y cómo retirarse. Esto solo cobra real significado entre quienes han alcanzado un conocimiento de la vida en la calle, es decir, tras haber vivido a la sombra de esta, cobijándose en su seno del frío y la lluvia, comiendo de su comida, bebiendo de sus líquidos. Con el tiempo pareciera diluirse la sensación de inseguridad que la calle produce en los iniciados, lo que no quiere decir que la calle no sea insegura. Por esto es que coincidimos con Robert Desjarlais, quien considera la calle como "un dominio sociogeográfico que modela una forma de vida específica y ciertos marcos de entendimiento" (Desjarlais, 1997: 120; traducción libre).

Este marco sociogeográfico no solo es el suelo donde pisan habitualmente los "moradores de la calle", sino que es también el lugar de la copresencia de y la cohabitación con otros individuos (transeúntes, consumidores, ciudadanos, pobladores). En este marco, la calle es simbolizada de dos maneras: 1) como si se tratara de un territorio prístino que se debe descubrir y nombrar y en el cual cada cual se sustrae más o menos de su historia pasada para mimetizarse en el cemento, los sitios eriazos, las construcciones abandonadas, los lugares liminales y los no lugares. 2) Como un territorio cuyas riquezas han sido ya extraídas y que, por efecto del tiempo, vuelve a alcanzar el estatus de potencia benevolente, por lo que requiere ser redescubierto y vuelto a nombrar. Estas dos formas pueden confluir entre sí y son las que explican el entendimiento que hacen de la calle quienes la habitan. De este modo, coexisten nociones de la calle como contexto existencial, es decir, a la vez como espacio en que deviene la vida y la muerte y como fuente de consistencia o borramiento vital en el que es posible registrar relaciones más o menos estandarizadas, contingentes y azarosas de benevolencia, indiferencia, silencio, abuso y violencia. La calle era para $C$ un espacio de apropiación creativa en la que se podía encontrar, más allá de toda su riqueza y desigualdad, lo necesario para vivir y dotarse de una identidad idiosincrásica. Un sitio en el que dejar inscrito su paso efímero, marcado por el ritmo de la conversación interior. Para $P$, en tanto, la calle era ese escenario en el que bullían fragmentos de una cultura indescifrable, de la cual él parecía irse desprendiendo cada vez más, no para retirarse a vivir en la soledad sino para distanciarse de su semántica, sus lugares comunes y su atosigante serialidad y replicabilidad. Las estrategias de sobrevivencia trascienden aquí las necesidades biológicas: el yo es a fin de cuentas lo que mayormente deberá proteger quien hizo de la calle su hogar. Nuestro análisis sugiere que, entre otras prácticas, la locura, el silencio, el ocultamiento, la evasión física o mediante sustancias, constituyen mecanismos que permiten asegurar la vida en estas condiciones $y$, en este sentido, pueden entenderse como prácticas de sobrevivencia.

Se podría pensar que los casos elegidos no son para nada típicos y que, con ellos, el etnógrafo no estaría ofreciendo sino cuadros efectistas y subjetivos del mundo de la marginalidad extrema, en lugar de descripciones detalladas de totalidades. Es perfectamente posible que así ocurra si el etnógrafo no ha tomado antes una posición. Personalmente diría que los casos fueron elegidos en tanto casos extremos de "sin-hogarismo" en tanto una forma de experiencia límite. En estos casos, además, se apreciarían diferencias en los modos de habitar y simbolizar la ciudad y a través de ellos, asimismo, sería posible revisar y repensar algunas opiniones y nociones comunes dentro de la cultura dominante.

Saber dónde ir a dormir, dónde pedir dinero, encontrar abrigo o refugio, comida gratuita o por poca plata, son conocimientos pragmáticos que sugieren que los "moradores de la calle" no son individuos más o menos fantasmales que divagan por la ciudad delirando o sin ningún rumbo fijo, como podríamos aducir del caso de P. Porque precisamente $\mathrm{P}$ buscaba donde pernoctar o conseguir ropa, comida y agua es que su mundo, por más delirante que pueda parecer a través de su verborrea y expresión escrita, no era completamente ajeno a algún tipo de orden, a 
alguna distribución de la actividad cotidiana en tiempos, en desplazamientos espaciales, a algún sistema de digresiones discursivas socialmente concebido como desequilibrio, el contramundo frente al mundo. En el caso de $C$, se desarrolla una apropiación del espacio urbano que es coherente con las concepciones subjetivas en torno a la función social autoasignada del marginal en la ciudad. Su mundo depende de una construcción simbólica sustentada en creencias y concepciones en la que parece existir una armonía entre las máximas de vida religiosa y los actos concretos. Se trata de una vivencia límite que da origen a una forma de sobrevivencia creativa en la que se condensa la actividad simbólica y que obliga a relativizar nuestros conceptos de lo deseable así como de lo puro-impuro, lo limpio-sucio, el trabajo-la improductividad.

La libertad es otro atributo adscrito a las personas que viven en la calle. Esta opinión es recurrente incluso entre los etnógrafos, pero es muy común encontrarla en ciertas representaciones idealizantes que ven en el "vagabundo" a una figura totalmente desarraigada y sin ataduras relacionales, así como profundamente ajeno a las pesadas estructuras materiales que gobiernan la vida social, política y económica de la sociedad moderna. La investigación empírica de este aspecto nos muestra más bien que tal desconexión absoluta es poco probable, aunque hay excepciones. El caso de $C$ es un extremo y una paradoja, por cuanto para vivir él necesita lo que otros desechan. Su relación con la sociedad está mediada por su relación con los desechos urbanos. Así, él se relaciona con lo que la sociedad arroja, asumiendo el compromiso de recoger y "limpiar" la ciudad. La resonancia semiótica del delirio, en tanto, también puede interpretarse como una forma de liberarse de los formatos hegemónicos del discurso, o como parte de una infrapolítica inconsciente para el propio agente. De cualquier forma, ¿qué libertad puede haber allí donde hay ausencia de reciprocidad o posibilidad alguna de comunicación intersubjetiva? Las principales ataduras que en estos casos pueden existir parecen ser finalmente de orden lingüístico. Todo lo que se dice busca hacer comprensibles estados y procesos del mundo, de la subjetividad y los otros, por más inverosímiles, erráticos e incoherentes que nos parezcan esos discursos. Por último, suele asociarse la libertad con la movilidad geográfica, con el nomadismo. Ni C ni P nos sirven de mucho para demostrar esta asunción ${ }^{11}$. En todo caso, la diversidad del mundo de las personas que viven en la calle ofrece esta posibilidad a través de la categoría de los "caminantes" 12 . De este modo, podría decir que las experiencias límite de los "moradores de la calle" pueden desplegarse en movimiento -como entre los "caminantes"- y, de allí, dar lugar a la sensación de libertad que ese estado podría suscitar; o bien que pueden estar ancladas a un único lugar en el cual queda inscripto el anonimato y la desafiliación relativa de cada uno. Así, si mantenemos la idea de homologar "vagabundos" con "caminantes", tendríamos que señalar que a estos se han sumado hoy día otros, más arraigados o sedentarios.

\section{Breve excurso de la etnografía de los "mora-} dores de la calle" en Temuco

Cuando a fines de 1997 inicié el "estudio sustantivo del estilo de vida de una clase marginal de personas" como las que acaban de ser presentadas (y muchas otras), intuía que se me impondría "una tarea tan densa como cuando uno debe enfrentarse a una cultura extraña" (Berho, 1998a: 38). Una década después veo ese objeto de estudio como parte de un campo de relaciones y significaciones humanas complejo en el que las experiencias personales de "vagabundos", "caminantes", "torrantes", "profesionales" y "alucinatorios" 13 se encuentran indisolublemente ligadas a los procesos sociales y subjetivos que acompañan y condicionan material y simbólicamente las suertes individuales. En este marco, la et-

11 Probablemente pudo valer al comienzo de las "carreras" de cada uno, cuando ambos vivían en otras regiones y en el trayecto a Temuco tuvieron conductas nómades. Mas este hecho no establece por sí mismo la especificidad identitaria de cada uno.

12 El caminante constituye una endocategoría presente especialmente entre personas que viven en la calle, jóvenes -menores de 40 años-, cuya principal característica consiste en la movilidad geográfica que los identifica. Comparten con los "torrantes" la adicción al alcohol y el desarrollo de prácticas como la mendicidad (o "macheteo") y el uso de los espacios asistenciales.

13 Categorías etnográficas levantadas y reconstruidas permanentemente por el autor desde 1998. 
nografía de las personas viviendo en la calle implica el extrañamiento cognoscitivo frente a la propia sociedad y cultura del etnógrafo, reafirmando la tesis de que su estudio impone la densidad simbólica de la acción humana de la misma manera que lo puede constituir la experiencia de enfrentarse a una cultura extraña ${ }^{14}$. Afirmar que "no todas las personas de la calle son iguales" me resulta hoy en día una obviedad; los "voluntarios de calle" saben mejor que nadie que es así. El problema es construir conceptualizaciones antropológicas de los fenómenos. Es decir, conceptualizaciones que, desencapsuladas de los marcos cognoscitivos y sociales particulares, contribuyan a la ampliación del entendimiento de la acción y el discurso humano ${ }^{15}$. De allí que considere que la etnografía es más que un instrumento metodológico para registrar y exponer textualmente la realidad social y desarrolle la idea de la etnografía como el enfoque teórico metodológico más importante de la antropología sociocultural. Lo que nos permite saber qué investigar y cómo hacerlo y también lo que podemos escribir y cómo escribirlo. Es también una actitud frente a los hechos, a las ideas teóricas y los métodos ortodoxos. Una posición frente al sentido común y el marco de valores del cual todos, sin excepción, arrancamos para hacer nuestras investigaciones: la que me lleva a hablar de "moradores de la calle" en lugar de "vagabundos"; la que me exhorta a hacerle más caso a los hechos y en ese marco a hablar de "marginalidades" en vez de marginalidad a secas y la que me conduce a pensar, sin duda, en los "vagabundos", los desahuciados de la sociedad, los ancianos abandonados, los "torrantes", los "discapacitados" pobres, en una palabra los excluidos de la sociedad nacional, como representantes de una categoría límite dentro de lo que pareciera ser un proceso alterno y contrario al "desarrollo" y al progreso social.
Porque esto es lo que enseña la etnografía de las personas que viven en la calle y su mundo y esto es a lo que el etnógrafo está llamado a descubrir detrás de las observaciones y las vivencias compartidas en el campo con los "otros": los contrastes, las irregularidades, las asimetrías, hiatos y antinomias de una sociedad que se autocomprende como moderna, pero en la que el individualismo abstracto y la igualdad jurídica son solo anhelos que enceguecen el futuro sin poder fundar aún relaciones menos desequilibradas. Así, el conocimiento etnográfico no solo se funda en la relación de campo con "otros", sino que lo hace en función de las diferencias y contrastes que el observador es capaz de visualizar y hacer inteligibles respecto de su propio mundo material, cognoscitivo y simbólico ${ }^{16}$.

\section{Bibliografía}

BERHO, M. (1998a), “Esbozo para una etnografía del vagabundo”. En CUHSO, 4 (1): 38-43.

BERHO, M. (1998b) "Condición sociocultural del vagabundo adulto en Temuco, con fines de reinserción social". Centro de Estudios Socioculturales - UCT, CORFOSAM, Temuco.

BERHO, M. (2000), "Una carrera hacia los bordes de la sociedad". En CUHSO, 5 (1): 45-56.

BERHO, M. (2002), “Identificando personas con discapacidad social. Informe de una experiencia de funcionarios del Servicio de Registro Civil e Identificación de Temuco". Dirección Regional de Registro Civil e Identificación, CES - UCT, Temuco, Chile.

BERHO, M. (2003a), "Perfiles socioculturales de personas sin hogar. Informe de sistematización", Programa de Apoyo a Personas Abandonadas en la Calle, DIDECO-Municipalidad de Temuco, Centro de Estudios Socioculturales, Universidad Católica de Temuco.

La etnografía del mundo de la vida de las personas que viven en la calle me condujo a la etnografía del marco de interacciones cotidianas de la persona y sus inscripciones simbólicas y colectivas y, de allí, al campo -si se quiere-más opaco de la sociedad y la cultura de los no marginales, sus relaciones y significados hacia los "moradores de la calle". Comienzo a ver la marginalidad como una cualidad relativa, como un proceso, en el que también se pueden visualizar tipos, tendencias o patrones de variadas índoles coexistiendo. Esta coexistencia fue analizada inicialmente (en Berho 2003b, op. cit.) respecto del modo como tres tipos institucionales diferentes conciben a las personas e interactúan con ellas.

15 Creo que aún no hemos podido construir y ofrecer explicaciones generales que, sin perder de vista la peculiaridad del objeto, avancen hacia una mayor comprensión del mismo y colaboren en el desarrollo de procesos de comunicación intra e intercultural en el mundo contemporáneo.

16 Iniciamos una exploración consciente de este principio el 2004, a propósito de lo que podemos denominar dialéctica "modelos - antimodelos" de persona. Los resultados preliminares de ese análisis se encuentran en Berho y Samaniego (2005a), op. cit. 
BERHO, M. (2003b), "Personas sin hogar en Temuco. Enfoque antropológico aplicado". En Nicolás Richard (ed.), Movimiento de campo en torno a cuatro fronteras de la antropología chilena, ICAPI, Guatemala.

BERHO, M. (2005), "Antropología de la marginalidad extrema. Una propuesta local”. En ANTHROPOS NN 207: 43-53.

BERHO, M. Y SAMANIEGO, M. (2005a), "El reverso de la identidad pública: modelos de persona en la sociedad y cultura contemporánea". En Actas del Primer Congreso Latinoamericano de Antropología, Rosario, julio de 2005.

BERHO, M. Y SAMANIEGO, M. (2005b), "Estudio multidimensional sobre la marginalidad extrema en la ciudad de Temuco". Informe final, Proyecto DIUCT 2003-1-01, Universidad Católica de Temuco.
BERHO, M. (2006), "Identidad marginal entre personas sin hogar de la ciudad de Temuco, Chile". Manuscrito inédito.

CABRERA, P. (1998), Huéspedes del aire. Sociología de las personas sin hogar en Madrid. Pontificia Universidad de Comillas. Madrid.

CASTEL, R. (1999), La metamorfosis de la cuestión social. Una crónica del salariado. Paidós, Buenos Aires.

DESJARLAIS, R. (1997), Shelter blues. Sanity and selfhood among the homeless. University of Pennsylvania Press, Philadelphia. 